\title{
'Dangerous and severe personality disorder': A psychiatric manifestation of the risk society
}

\author{
KEVIN CORBETT ${ }^{1} \&$ TRISTEN WESTWOOD $^{2}$ \\ ${ }^{1}$ University of York UK and ${ }^{2}$ Bournemouth University UK
}

\begin{abstract}
This paper analyses the newly proposed United Kingdom (UK) psychiatric diagnosis of 'dangerous and severe personality disorder' ('DSPD'). The aim is to show how the category of 'DSPD' manifests aspects of Beck's analysis of the 'risk society' and poststructural 'governmentality' approaches to understanding the notion of risk. Concepts such as 'dangerousness', 'violence' and 'risk' are critically reviewed in relation to 'DSPD' and are found to be less than objective. The paper interrogates the political underpinnings of this newly proposed diagnosis and analyses pre-existing frameworks of potential utility for developing further understanding of dangerousness and violent behaviour. Key issues are critically discussed in relation to the concept of 'dangerousness' including the reliability of assessment tools, the socioeconomic status of those potentially diagnosed with DSPD and detention without committing any prior offence. The paper also discusses the potential for conflict between the proposed legislation, the UK Human Rights Act 1998, healthcare practice and the likelihood of divided professional loyalties. The paper argues that this newly proposed public health policy has a sociopolitical rather than psychiatric rationale for justifying psychiatric detention and, as such, is a psychiatric manifestation of the late modern culture of risk.
\end{abstract}

\section{Background and introduction}

This paper critically explores a newly proposed diagnostic category of 'dangerous and severe personality disorder' (DSPD) in relation to its associated terms, concepts and ramifications. The current United Kingdom (UK) Mental Health Act outlines how the UK Department of Health $(\mathrm{DoH})$ plans to impact on future United Kingdom National Health Service (UK NHS) approaches to people diagnosed with personality disorder ( $\mathrm{DoH}, 2001)$. An official perception is promoted that the 'general public' has not been protected 'adequately' from those so diagnosed ( $\mathrm{DoH}, 2001$, p. 2), against whom popular 'tabloid' support for pre-emptive action has been garnered (Davenport, 2001; Sawer, 2002).

It is somewhat ironic that at roughly the same time as this policy's proposal, a film called Minority Report was released. Based on a short story by Philip K. Dick (1956), it describes a future society that imprisons individuals based on official

Correspondence: Dr Kevin Corbett, Lecturer in Nursing, Department of Health Sciences, C Block, Alcuin College, University of York, York YO10 5DD, UK. E-mail: kpc500@york.ac.uk 
prophecies of their likelihood of committing violent crime or 'precrime' (Dick, 1956). It is a 'fictional' example of Castel's analysis of the nature of our current prevention strategies (interestingly pre-dating Castel's own analysis) and their particular mode of surveillance-'predetection'-which functions to anticipate/prevent undesired events (Castel, 1991, p. 288). Thus, this newly proposed public health policy (and its diagnosis of 'DSPD') is concerned with the concept of 'dangerousness' and violent behaviour. It proposes the detention of diagnosed individuals, irrespective of any offence being committed, on the basis that they pose an unacceptable level of risk of violence to the public. Thus, it resonates with social representations (e.g. Minority Report) of people considered to be 'at risk' of becoming 'dangerous' (meaning violent) in the future; as well as analyses of the shift from corrective/therapeutic intervention to the probabilistic calculation of risk based on 'risk profiles' (Castel, 1991).

\section{Theoretical framework}

Lupton (1999) shows how the meaning of the concept 'risk' has changed over the centuries. It emerged first in the Middle Ages in relation to 'natural' dangers (e.g., storms, floods, epidemics), quite unrelated to perceptions of human fault and responsibility. In the seventeenth century it was derived from the Italian 'risco', being associated with gaming and gambling (Ayto, 1990). In modernity, 'risk' changed as it became scientized by mathematics/probability theory (Lupton, 1999, p. 6): the belief was that rational counting and ordering would redress disorder (Hacking, 1990). By the end of the nineteenth century the concept became located within the social/human realm (Lupton, 1999, p. 6), such that 'types of events can be subjected to supra-individual and political rules of recognition, compensation and avoidance' (Beck, 1992a, p. 99).

Today, 'risk' has attracted analyses across a continuum of realist to constructivist epistemological approaches (Lupton, 1999, p. 33). This paper draws on the constructivist epistemological positions in Lupton's schema by using 'risk society' (Beck, 1992b) and 'governmentality' or poststructuralist perspectives (Castel, 1991). We argue that what is understood as 'risky' or 'dangerous' about 'DSPD' is as much a product of historically, socially and politically contingent 'ways of seeing' as it is of 'objective', 'quantifiable' public health/psychiatric phenomena (Lupton, 1999, p. 35). Thus, 'risk' currently emerges as a governance function within the discourse of public health and health promotion (Lupton, 1994, 1995, 1999; Petersen \& Lupton, 1996); it serves to distance health promoters from a population (Petersen \& Lupton, 1996); enabling identification of individuals' 'risk profiles' within a 'risk society' where (often quantitative) 'risk appraisal' is paramount (Beck, 1992b).

'Danger' has been defined as 'exposure to harm', and 'dangerous' as involving or causing danger (Hawkins \& Allen, 1991). The Butler Committee (Home Office and Department of Health and Social Security (DHSS), 1975) claimed that there was no such psychological, objective or medical entity as a 'dangerous person'. Yet Butler did define 'dangerousness' as a propensity to cause serious physical injury or lasting psychological harm. Thus, it was an early example of how the notion of 'dangerous' was being replaced by that of 'risk' (of violence) (Castel, 1991; Lupton, 1996) as, in late modernity, authorities moves from institutional incarceration to political intervention to pre-empt undesired events within a 'hygienist utopia' that induces a 'delirium of rationality' (Castel, 1991, p. 289).

Beck defines 'risk' as 'a systematic way of dealing with hazards and insecurities induced and introduced by modernization itself' (Beck, 1992b, p. 21, emphasis in the original). Paul 
Boateng, former UK Health Minister, confirmed the 'rational' (absolute) nature of the modernization process now underpinning reform of mental health law:

Our new policy... must be underpinned by modern and robust legislation.... with our safety-plus approach, the law must make it clear that non-compliance with agreed treatment programmes is not an option. We will look to [our advisers] for clear advice on how to take forward a root and branch reform of the law. (Boateng, cited in Department of Health, 1998, emphasis added)

For Beck, risks emerge from 'the transformation of uncertainty and hazards into decisions' (Beck, 1996b, p. 30). Ill-defined threats are transformed into well-defined hazards via a process of instrumental rational control as a direct result of social 'modernization' (1996b, p. 30). Society as a whole becomes a 'provident state', a 'risk group' in the terminology of insurers.

In this 'risk society', well-defined hazards are produced that 'undermine and/or cancel the established safety systems of the provident state's existing risk calculations' (Beck, 1996b, p. 31, emphasis in the original). The social thrust of risk determination is towards the projection of future danger:

In the risk society, the past loses the power to determine the present. Its place is taken by the future, thus something non-existent, invented, fictive as the 'cause' of current experience and action. We become active today in order to prevent, alleviate or take precautions against the problems and crises of tomorrow and the day after tomorrow-or not to do so. (Beck 1992b, p. 34, emphasis added)

Dobos (1992) defines risk as belonging to a situation, of uncertain outcome, where something valuable could be lost. Thus, today the concept of 'risk' has now gained a somewhat exclusively negative connotation. It has shifted in meaning towards the assessment of the likelihood of adverse, as opposed to propitious, conditions (Castel, 1991; Hayes, 1992; Lupton, 1994, 1995, 1999). It parallels a shift whereby the notion of an actual subject is replaced by a set of 'risk factors' assessed by experts. It supplants the traditional doctor-patient relations inside a new space of risk (Castel, 1991) based on the probabilistic/abstract experience of risk, 'it does not start from a conflictual situation observable in experience, rather one deduces it from a general definition of the dangers one wishes to prevent' (Castel, 1991, p. 288, emphasis in the original). The resulting surveillance-'systematic' or 'scientific' predetection (literally akin to Dick's 'precrime') - is then practised on subjects under scrutiny who, in turn, are viewed as a combination of (risk) factors liable to produce risk: little more than 'statistical correlations of heterogenous elements' (Castel, 1991, p. 288). It enables the separation of diagnosis from treatment, the classifying of caring/assessment as an expert activity and the further subordination of practitioners to administrators (Castel, 1991).

The diagnosis of DSPD may adversely label patients as 'dangerous', conveying a propensity to cause violence or lasting psychological harm. Following on from Castel (1991), experts can then 'label' an individual, 'constituting' their risk profile and 'placing' them in a psychiatric 'career', irrespective of any 'care' actually received. Thus, the category of 'DSPD' itself is a new hazard/insecurity introduced via UK NHS modernization and other social processes of defining future hazards, not an actual experience, which then acts to undermine and/or cancel the currently established safety systems for management of calculable risk within pre-existing mental health law and inpatient units. For any person so diagnosed, this 'risk society' may constitute them as unmanageable, such that increasingly complex systems of rational control are required to ensure future public safety; like the proposed 'high security psychiatry services' for those in the future diagnosed as having 'DSPD' (DoH, 2001). As Boateng's statement starkly implies, 


\section{K. Corbett E T. Westwood}

this proposed approach seems a pragmatic means for control, one that has little concern for any human/social cost in seeming to eradicate risk 'as though one were pulling up weeds' (Castel, 1991, p. 299).

\section{The social construction of 'dangerousness'}

The National Service Framework for Mental Health (DoH, 1999) estimated that there are over 2000 individuals (98\% male) suffering with 'DSPD' in England and Wales, most being detained either in prison or secure hospitals. Despite the Butler Committee's conclusions (Home Office \& DHSS, 1975) that 'psychopathic disorder' was not a meaningful concept, it survived into the UK's 1983 Mental Health Act (DoH, 1983) and the term 'Antisocial Personality Disorder' ('APD') was suggested as an alternative. The term 'DSPD' may have arisen from the original term 'psychopathic disorder', defined as: 'a persistent disorder or disability of mind which results in abnormally aggressive or seriously irresponsible conduct on the part of the person concerned' (DoH, 1983, section 1(2), p. 76). However, at least one official definition of 'DSPD' embodies a range of social as opposed to purely psychiatric references:

[those people over 18] who have an identifiable personality disorder to a severe degree, who pose a high risk to other people because of serious antisocial behaviour resulting from their disorder... [the] overwhelming majority are people who have committed serious offences ... a small minority who have not committed any serious offence remain at large in the community. (DoH, 2001, p. 5, emphasis added)

It also conveys the sense that 'high-risk' people are 'remaining at large', implying the failure of established safety systems/risk calculations, and further implying a new need for more rational control. Thus, there is concealment of social as opposed to psychiatric ramifications, suggestive of action in the here and now to prevent future catastrophe, and further resonating with Beck's analysis (Beck, 1992b).

The National Institute of Mental Health's Epidemiological Catchment Area Survey examined the relationship of violence and mental disorder through 10000 structured interviews (Swanson, Holzer, Ganju \& Tsutomu Jono, 1990). In total, 2.1\% of those not meeting the Diagnostic and Statistical Manual of Mental Disorders (DSM) criteria for 'mental disorder' self-reported perpetrating violence in the previous year; $59.3 \%$ of those meeting the criteria for 'personality disorder' reported committing such acts. Although having a large sample size, the study's confounding factors included social desirability (Kinsey, 1947) and evaluation apprehension (Coolican, 1994). Respondents in contact with the psychiatric services may have been more experienced in interview technique and so more open to disclosing personal information perceived as negative. Thus, it can be argued that the causal/correlative 'link' between 'mental disorder' and 'dangerousness' appears more like an artefact of research methodology and not an objective empirical finding.

Nietzel, Speltz, McCauley and Berstein (1998) reviewed the literature on the development of 'PPD' (psychopathic personality disorder) into 'APD' citing the diagnostic criteria given in the DSM IV, namely: failure to conform to social norms; deceitfulness/lying; failure to plan ahead; irritability or aggressiveness; disregard for safety; failure to sustain consistent work or pay debts; lack of remorse regarding hurting or stealing from another; and the individual being at least 18 years of age. Given the nature of the latter, an alternative analysis is that these predominantly working-class males may have been displaying typical behaviour within their sub-culture(s). A young, poor male may be unlikely to want to conform to 
social norms/values when he may feel alienated by those very norms/values. Thus, under such conditions it may be hard to plan ahead or not to be irritable.

Furthermore, the social backgrounds of those experts involved in creating/applying such diagnostic criteria may be radically different from those receiving the diagnosis. For example, the former may be from more middle-class backgrounds and thus may feel more positively orientated towards society. Regarding 'social judgements', Nisbett and Ross (1980) comment on the shortcomings of human inference within their studies in the field of social psychology. The term 'APD' may be a misnomer if those imparting such diagnoses do not identify with the same social norms/values as those alluded to by the diagnosis itself. It could be argued that identification with the same social norms/ values could be a prerequisite for any physician to label an individual as being 'antisocial'. Thus, it may be further argued that the concept of 'cultural relativity' (Coolican, 1994), which asserts that the sub-cultural norms of people's behaviour should be taken into account, is not being exercised by those generating/imparting such diagnoses as 'APD', 'PPD' or 'DSPD'.

In a meta-analysis of the outcomes of the mental health review tribunals and earlier UK mental health policy, Gostin (1985) points to the cultural shift that portrays people diagnosed with mental health problems as 'bad' rather than 'mad'. Gostin describes the slippage underpinning the sociopolitical control over those ascribed 'bad' rather than 'mad': originally punishment was seen as desirable and then retribution was seen as 'just desserts'; later moral reasons were seen as a good cause to punish someone; after that the argument was put forward that punishment was a deterrent to such undesirable behaviour. This was followed by the opinion that punishment was the only way to treat this sort of disorder (Gostin, 1985). Thus, it may be argued that as each of these reasons has fallen out of favour, an even less persuasive 'public protection' argument has emerged as a sociopolitical, rather than a psychiatric, rationale for justifying psychiatric detention. This hyper-rational approach to the coupling of risk/dangerousness may make 'the psychiatrist into an advisor to ruling politicians, or an auxiliary to administrative "decision makers", (Castel, 1991, p. 286, emphasis in the original).

\section{Quantifying and predicting 'risk'}

Since the 1970s, mental health professionals have been concerned with the quantification and prediction of the level of dangerousness/risk as posed by patients. Monahan (1984) described how a generation of these predictions were traditionally based on clinical interviews that focused on two main issues as an indicator of proclivity to reoffend: the diagnosis of the patient and the nature of the offence(s) already committed. Monahan concluded that clinical predictions were useful and accurate in the short-term, whilst others have refuted this claim based on the vast variety of variables at play (e.g., Steadman \& Cocozza, 1980). Refutation of any probability claim (Steadman \& Cocozza, 1980) led to multi-variable assessments that account for personality factors (Megargee, 1976) and situational aspects (Monahan, 1988).

More emphasis was subsequently placed on sociological, psychological and biological factors and an established history of violence, as indicators towards the assessment of future violent behaviour. Quinsey (1995) went so far as to develop a scientific formula for assessing/predicting 'dangerousness', which included all of the criteria deemed as important in previous research: $\mathrm{P}(\mathrm{D} 2)=\left(\left(\mathrm{B} 2{ }^{\star} \mathrm{P} 2{ }^{\star} \mathrm{E} 2\right)-\left(\mathrm{B} 1{ }^{\star} \mathrm{P} 1{ }^{\star} \mathrm{E} 1\right)\right)$ where $\mathrm{P}(\mathrm{D} 2)$ equals the probability of future dangerousness; B2, P2 and E2 refer to psychological, biological and environmental factors valid at the time of examination, and B1, P1 and E1 are the 
same factors occurring in the past when violent acts were carried out. Using this formula, an elevated probability of further dangerousness is indicated when the values for past and present become closer and nearer to zero is the value for future dangerousness.

Such predictive and quantifying frameworks may appear impressive. However, the newly proposed policy is based on the probabilistic/abstract experience of risk, instances of which are not observed in experience but are deduced from a general definition of the dangers one wishes to prevent (Castel, 1991, p. 288). Thus, it is debatable whether in psychiatric contexts these formulations, like their corollary surveillance systems ('scientific' or 'systematic' predetection) (Castel, 1991, p. 288), are truly meaningful, useful or even ethical. As such, they are further manifestations of the 'risk society' (Beck, 1992b) whose social impetus is always future orientated.

\section{Psychiatric approaches to violent behaviour}

Given that terms like 'risk' and 'dangerous' are value-laden, ethereal and subjective, it is important that they are not reified without any qualification. This becomes more crucial when differing theoretical approaches can be used interchangeably in order to define, assess and treat 'DSPD'. Dallos (1998) identifies five main, yet differing, theoretical approaches that pre-date the emergence of 'DSPD'. The latter are explored below in respect of their theoretical import for 'DSPD' given this newly proposed policy's particular linkage of 'DSPD' to 'dangerousness' and the 'risk' of violence.

First, psychodynamic approaches assert that the experiences of early childhood have an effect on and are the primary cause of later problematic behaviour. Treatment focuses on revealing and resolving these prior experiences thereby promoting autonomy. Norton and Dolan (1995) argue that the authoritarian parent-like responses of many psychiatric institutions serve to perpetuate patient transgressions, given that institutions serve as guardians for the needs of society and may not always meet people's therapeutic needs. Similarly, Adshead (1998) argues that acknowledging how psychological development/ functioning are affected by our earliest attachments is useful in managing behavioural disturbances in psychiatric settings.

Second, humanistic frameworks (e.g., Rogers, 1961) suggest that people are essentially creative and motivated to grow. They emphasize self-direction and the use of art, music, writing and drama as means for dealing with hurtful experiences. Self-help groups are an offshoot of this type of approach, which eschews interpretation and diagnosis by a therapist. Wilson and Kneisl (1988) argue that humanism within psychiatry means keeping focused on a devotion to the interests of clients irrespective of their status/culture. Rigorous legislation or overly authoritarian behaviour may be seen as non-humanistic.

Third, systemic frameworks view people's problems as being rooted in the patterns of communications within their relationships rather than within the individual. This approach is mostly used in families and emphasizes the development of shared meanings. It aims to affirm common realities and its emphasis on communication resonates with those who see madness per se as stemming from society's treatment of the mentally ill (Johnstone, 2000; Laing, 1960). Morrison's (1998) study of the culture of care-giving and aggression in psychiatric settings highlights that staff perceptions of the organization are a key factor in constructing precisely the types of behaviours they are designed to minimize. Violence is then a response to the threatening attitudes within institutions, in the context of the relationship between skill mix and diagnostic categories (Owen et al., 1998).

Fourth, behavioural frameworks contend that psychological problems are acquired through learning experiences mediated by the use of punishments and rewards. 
Treatments may be systematic desensitization; behaviour modification, such as the use of token economies (LePage, 1999); and cognitive behavioural approaches. The notion that violent behaviour can be learned/reinforced is validated by Morrison (1994), who reported that violent psychiatric patients in low secure wards most utilized a coercive interaction style, involving the manipulation of others for personal gain. This style of relating was a more powerful predictor of future violence than a history of violence (Morrison, 1994).

Fifth, biomedical/genetic frameworks imply that personality disorders are solely a result of brain deficiencies like neurotransmitter problems or genetic abnormalities. Whilst investigating sex chromosome abnormality and its relationship to violence, Gotz, Johnstone, and Ratcliffe (1999) reported that rates of criminal conviction between 17 XXY men, 17 XYY men and 60 controls were not significantly different. The latter showed only a slightly increased liability to antisocial behaviour in the XYY men and no increase in criminal convictions among the XXY men. The small sample size was related to the low discriminatory power of this study and was offered as a criticism by the researchers for non-significance. Another approach to understanding violence is the search for neurological correlates. If functional/structural changes in the brain are found to be associated with violence then labelling and directives for subsequent treatment of dangerousness may be rationalized. Damage to certain areas of the brain's limbic system and the temporal and frontal lobes have been associated with violent behaviour (Garza-Trevino, 1994), as have temporal lobe epilepsy and Alzheimer's disease (Garza-Trevino, 1994).

However, that genetic, endocrine or neurological anomalies correlate with violence and thus adequately account for most violent behaviour is questionable. For example, Kalat (1992) showed that the highest incidence of violent behaviour is reported in males aged 15-25 years who are also reported as having the highest testosterone-blood ratio. Yet it would be absurd to infer that every male exhibiting violence, and aged between 15-25 years, is violent due to having a higher proportion of serum testosterone. Kalat (1992) concludes that biological factors may cause violent behaviour in a minority of individuals and account for a proclivity in others, whilst the importance of the physical and social environments should not be underestimated.

Given the above theoretical approaches and their possible utility in terms of the proposed behavioural characteristics of DSPD, it is important to note that the framework proposed by the UK Department of Health (DoH, 2001) is behavioural/biomedical/genetic. Furthermore, the fact that such a framework is being promoted does not make it more 'true' or 'accurate' than any other. Any chosen framework may tell us more about the authority doing the choosing than those to whom it is directed, given that each framework is usable and each is also 'political' (Chesler, 1972; Cooper, 1971; Laing, 1960). The privileging of one framework over another can indicate something about those authorities that undertake the 'choosing' on behalf of society. Thus, we argue that this choice of framework for conceptualizing and situating 'DSPD' and 'APD' (and associated treatments) reflects not only the ascendancy of risk discourse within psychiatry, itself another manifestation of the 'risk society' (Beck, 1992b) but also the political attractiveness of basing psychiatric practice on risk perceptions to appease concerns over public safety.

\section{Psychiatric detention, 'dangerousness'/'risk' and violence}

Vinestock (1996) asserted that the concept of 'risk assessment' is clinically/politically fashionable. Whilst this claim acknowledges the political context of this topic, it appears to simultaneously postulate a causal link between mental illness and violence, based on 
research involving only four case studies of patients and an analysis of the 'risk assessments' and 'mental state examination' process. Vinestock noted that those with limited experience of psychiatry may fear violence from the mentally ill and perceive the latter as dangerous and noted further that 'while this may be due to prejudice, there is robust research evidence to show that there is a link between some aspects of mental disorder and violence' (Vinestock, 1996, p. 3). With increasing litigation, Vinestock suggests that the public perception is that psychiatrists (as 'experts') should be able to decipher which clients are dangerous to others as society sees them as culpable when violence by patients is reported (Castel, 1991).

The sociopolitical context of psychiatric risk assessment has recently become a more pressing topic with media exposés (Davenport, 2001; Sawer, 2002). Yet media coverage of mental health topics is biased towards themes of 'violence to others' (Philo, Secker, Platt, Hendersen \& Burnside, 1994; Ramon, 1996). When a UK court receives an application for a compulsory treatment order, the judge needs to consider whether the individual presents a 'serious danger'. Following on from Cooper's (1994) analysis, under the newly proposed legislation 'serious danger' could be defined as an imminent, demonstrable risk of no less than severe physical violence, not reasonably preventable in the absence of compulsory treatment. Thus, the newly proposed legislation could help confirm as 'true' a correlation between detention and violence despite a lack of epidemiological evidence (Taylor \& Gunn, 1999). Therefore, the recent UK Government's interest in controlling dangerous mentally ill people may be fuelled by political needs and media sensationalism rather than a thorough or truly rational consideration of the evidence. It might seem that such political influence is a new phenomenon and that 'government' and 'psychiatry' are mutually exclusive domains.

Foucault's analysis of the emergence of psychiatry is useful for making explicit the changing rationales that underpinned the emergence of psychiatric confinement:

Before having the medical meaning we give it, or that at least we suppose it to have, confinement was required
by something quite different from any concern with curing the sick. What made it necessary was an imperative
of labour.... From the beginning the institution [1'Hopital General in Paris] set itself the task of preventing
'mendicancy and idleness as the source of all disorders'...this was the last of the great measures that
had been taken since the Renaissance to put an end to unemployment or at least to begging. (Foucault, 1961,
pp. 46-47, emphasis added)

Warner's more recent analysis echoes Foucault in terms of making transparent the relationship between the economy and mental health as well as its policy impact:

Efforts to rehabilitate and reintegrate the chronically mentally ill will only be seen at times of extreme shortage of labour-after the other battalions of the industrial reserve army have been mobilised. At other times, the primary emphasis will be one of social control. (Warner, 1994, p. 137, emphasis added)

Swanson et al. (1990) argue that perceptions of violent behaviour (rather than 'mendicancy and idleness') are now at the core of contemporary thinking on psychiatric disorder, such that violence and mental disorder are becoming synonymous. In a meta-analysis of the studies on the topic of violence and the mentally disordered (from different sources and from different perspectives), Monahan (1984) concludes that there is a limited connection between mental disorder and violence. Whilst Arboleda-Florez (1998) found an association between mental illness and violence, as many factors are known to be out of the patient's control (Stokman, 1984) so causality cannot be truly established. In a meta-analysis of clinical judgements and statistically derived ratings for 'dangerousness' across 23 studies, Buchanan and Leese (2001) analysed the sensitivity/ specificity of these studies in relation to the base rates of violence in people with 
'DSPD', finding that six of those so diagnosed would need to be detained just to prevent one violent act.

In the Foreword to Reforming the Mental Health Act (DoH, 2001), Alan Milburn (former UK Minister of State for Health) describes how existing Mental Health laws only provide compulsory powers for inpatients. Milburn highlights how most patients are treated in the community, consequently building the case for community extension of compulsory powers. Thus, primary prevention policy is now reconstituted as being unable to act on the social conditions producing this newly perceived 'risk' by the more traditional means of communication via the education system, the mass media and professional/lay interactions (Caplan, 1964, cited in Castel, 1991). Contrary to Castel's (1991) analysis, authorities now view the possibility of risk prevention by forceful confinement of those so predetermined as well as by widening psychiatry's therapeutic role, given that any new category of inpatient, once so confined, may become a legitimate public health focus for therapy previously denied/postponed.

Goldacre (2002) talks of the 'political psychiatric diagnosis' like that used against political dissidents in cold war Russia and the Soviet system of detention. Goldacre (2002) argues that the newly proposed Mental Health Act goes against prevailing UK mental health opinion, given that the term 'DSPD' was not a diagnosis generated from within psychiatry, but a 'political diagnosis' originating in the Department of Health's Green Paper (DoH, 1999). In attempting to show how dubious are such 'political diagnoses', Goldacre cites the case of General Grigorenko who became interested in Stalin's persecution of Crimean Tartars. He was subsequently interned within a Soviet asylum with a diagnosis of 'pathological paranoid development of the personality with the presence of reformist ideas' (Goldacre, ibid., p. 4). To summarize, the concepts of 'risk', 'dangerousness', violence and 'psychiatric detention' come together with the definition of the politically inspired diagnosis of DSPD. Thus, as per Beck's analysis of the 'risk society', so-called newer forms of psychiatric control (i.e. 'confinement') will have to be planned in order to limit inadmissible future risk of those likely labelled as having 'DSPD'. It represents a reconstitution of a mode of social/psychiatric control ('confinement' or 'incarceration') within a framework of risk and its associated predetermination.

\section{The United Kingdom Human Rights Act 1998}

The 'treatability test' in the 1983 Mental Health Act states that a person with 'PPD' should only be detained if doing so is likely to alleviate or prevent further deterioration in the patient's condition. The question remains: how does an individual with 'APD'/ 'PPD'/'DSPD' have his/her condition alleviated or prevented from getting worse by being forcibly detained without having committed any offence? Wilson (2002) commented that thousands of patients could be entitled to invoke the European Human Rights Act (European Court of Human Rights, 1998) and claim for damages after a recent precedent was set where a judge found that the Department of Health had, on a regular basis, breached the rights of those forcibly detained under the Mental Health Act in UK hospitals. Article 3's clause on 'prohibition against inhuman, degrading treatment or torture' may be invoked for those potentially detained and diagnosed as having 'DSPD', as it may be argued that detention without offence is tantamount to torture. Following on from this, regarding detention itself, Article 5 of the Act (the right to liberty and security of the person) is likely to be invoked most frequently as it is contravened by detention without committing an offence. Discrimination is covered by Article 14 of the Act, which 
may be invoked due to the diagnosis of 'DSPD' causing the individual not to be seen as innocent until proven guilty, unlike the rest of society. Article 14 may also be invoked due to the almost exclusive population of young working-class males that might possibly be labelled with this diagnosis.

\section{Conclusions}

The above analysis has revealed that the concept of 'DSPD' manifests several aspects of the 'risk society' (Beck, 1992b) and poststructural analyses of risk (Castel, 1991). First, the UK NHS modernization process currently under way, and its reappraisal of risk, has led authorities to redefine the risk posed by those psychiatrically labelled with personality disorder ('ADP' etc.). If the new proposals eventually become law, these individuals will then be considered as constituting some sort of inadmissible threat to public safety.

Second, in this politically inspired redefinition process, 'hazards' appear to have been made less 'hazardous' but the result may will be to undermine the established safety systems of the UK NHS and its own pre-existing risk calculations. The social impetus of this political redefinition is forward looking as described in Beck's analysis because, in order to adequately contain the newly configured 'hazard', a new psychiatric infrastructure of detention, diagnosis and legislation will need to emerge. It illustrates how (and contrary to Castel's [1991] analysis) social administration is moving in late modernity from the political intervention much loved by preventive psychiatry with its emphasis on re-engineering of social environments (Caplan, 1964), towards a newer rationale for incarceration, namely that of 'systematic' or 'scientific' predetection. Thus, the rationale now for incarceration clearly moves beyond that of mendicancy/idleness (Foucault, 1961) or even rehabilitation, towards that of greater social control (Warner, 1994), based on probability and psychiatric labelling. We argue that these developments further signify a crisis of legitimacy (or even failure?) for contemporary psychiatry and its proponents in the United Kingdom, as generally alluded to (unrelated to 'DSPD') by others (Clarke, 1999; Coppock \& Hopton, 2000). Even in parts of the USA, where some provision exists for detaining those perceived as 'dangerous', a court trial (not the attending physicians) determines beyond reasonable doubt any continuing risk of dangerousness (JUSTICE, 1999).

Third, psychiatry may lose its power to determine the present approach to those so diagnosed, as the chosen future approach becomes based on something calculable but non-existent (Castel, 1991). Like the concepts of 'precrime' in Dick's dystopia (Dick, 1957) and 'predetection' (Castel, 1991), the inadmissible risk of someone diagnosed with DSPD committing future violence may seem 'fiction-like', but if the newly proposed legislation is enacted such stochastic prophesies may quickly become the 'cause' of current experience and action. Again this surpasses even the statute in Kansas in the USA, where a finding of 'dangerousness' is, in itself, insufficient grounds for recommending indefinite detention (JUSTICE, 1999).

Fourth, the sociopolitical determinants of mental health law, which many might assume are premised on so-called 'objective' criteria, are found in the above analysis to be more social, connotative and conceptual rather than 'actual'. Thus, an appropriate question is raised about the scientific/psychiatric rationale(s) for creating a new diagnostic category like 'DSPD' (and its associated categories like 'APD'). Subsequent research may answer the latter question whilst giving further evidence of the political context of psychiatry, given that authorities privilege a behavioural/biomedical/genetic framework in psychiatric 
treatment of those who will be diagnosed as having 'DSPD'. It could be argued that the latter appears to be driven more by the political appeasement of an electorate in relation to poorly defined notions of 'public safety' and sensational exposés of violence committed by discharged psychiatric patients (Ramon, 1996) rather than by attention to any evidence. It is this manifestation of the late modern risk society, with its political underpinnings, which we argue is of potential concern for human rights.

Fifth, it is important to highlight the socioeconomic bias in the diagnosis of 'DSPD' with $98 \%$ of clients in one study being male, mostly under 25 and from working-class backgrounds (Nietzel et al., 1998). Given that research already gives clear evidence that poverty and alienation are associated with antisocial behaviour, and that the cultural relativity of those generating/imparting diagnoses potentially confounds the scientific/ psychiatric legitimacy of such diagnoses, it could be argued that the latter constitute important rationale(s) for future research into the biases in the development of both the diagnostic criteria and the process of diagnosing 'APD', 'PPD' and 'DSPD'. It may also shed light on the socioeconomic factors that help create 'antisocial' behaviour, which preventive psychiatry aims to address (Caplan, 1964).

Finally, another important issue is the future impact on UK healthcare practitioners. In other countries, such as Holland, where continued detention exists, it is argued that healthcare practitioners should not advise courts on whether to impose detention. Dutch healthcare practitioners are reportedly overreactive in risk assessment, erring on the side of over-protection (Blankstein, 1988). The UK Nursing and Midwifery Council's (2002) Code of Professional Conduct cites in its first clause (1.2) that Registered Nurses should: 'Protect and support the health of individual patients and clients' (p. 3). Although further clauses talk about protecting the public, and working in accordance with the law, much of the above-mentioned research and the European Human Rights Act appears to point towards a potential 'double bind' for UK healthcare practice. This 'double bind' could be seen as one of divided loyalties. On one hand, practitioners have a loyalty to the authorities that argue for the detention of those people labelled as 'DSPD'; on the other hand, practitioners will have a loyalty to promote the rights and therapeutic treatment of such clients within the public healthcare system. UK healthcare practitioners may therefore find themselves increasingly in a position of being instruments of a political agenda surpassing that of their peers in countries with continuing detention (Blankstein, 1988; JUSTICE, 1999). They may become more subservient to administrative exigencies as predicted by Castel (1991), within the official instigation of a politically motivated law of 'detention without offence', whilst simultaneously trying to preserve the rights and therapeutic treatment of patients/clients.

\section{Acknowledgements}

The authors would like to thank their colleagues who kindly gave feedback on earlier drafts of this paper, including the anonymous reviewers of Critical Public Health.

\section{References}

Adshead, G. (1998). Psychiatric staff as attachment figures. Understanding management problems in psychiatric services in the light of attachment theory. British Fournal of Psychiatry, 172, 64-69.

Arboleda-Florez, J. (1998). Mental illness and violence: An epidemiological appraisal of the evidence. Canadian Revue of Psychiatry, 43(10), 989-986. 


\section{K. Corbett $\mathcal{G}$ T. Westwood}

Ayto, J. (1990). Dictionary of word origins. London: Bloomsbury.

Beck, U. (1992a). From industrial society to the risk society: Questions of survival, social structure and ecological environment. Theory, Culture and Society, 9, 97-123.

Beck, U. (1992b). Risk society: Towards a new modernity. London: Sage.

Blankstein, H. (1988). Organisational approaches to institutional estimations of dangerousness in forensic psychiatric hospitals: a Dutch Perspective. International fournal of Law and Psychiatry, 11(4), 341-345.

Buchanan, A., \& Leese, M. (2001). Detention of people with dangerous severe personality disorders: A systematic review. Lancet, 8(9297), 1955-1959.

Caplan, G. (1964). Principles of preventive psychiatry. Boston: Basic Books.

Castel, R. (1991). From dangerousness to risk. In Burchell, G., Gordon, C \& Miller, P. (Eds.), The Foucault effect. studies in governmentality (pp. 281-298). London: Harvester Wheatseaf.

Chesler, P. (1972). Women and madness. New York: Doubleday.

Clarke, L. (1999). Challenging ideas in psychiatric nursing. London: Routledge.

Coolican, H. (1994). Research methods and statistics in psychology. London: Hodder and Stoughton.

Cooper, D. (1971). The death of the family. London: Penguin.

Cooper, R. (1994). Predicting violence in newly admitted inmates: A lens model analysis of staff decision making. Criminal fustice and Behaviour, 17(4), 431-447.

Coppock, V., \& Hopton, J. (2000). Critical Perspectives on Mental Health. London: Routledge.

Dallos, R. (1998). Mental health matters. London: Open University.

Davenport, J. (2001). Yard pinpoints would-be murderers, Daily Mail, 27(November), p. 6.

Department of Health (1983). Mental health act. London: HMSO.

Department of Health (1998). Expert adviser appointed to start review of the mental health act. Press Release 98/391 London: Department of Health.

Department of Health (1999). National service framework for mental health: Modern standards and service models. Cm 4386 London: HMSO.

Department of Health (2001). Reforming the mental health act. Cm 5016 I/II London: HMSO.

Dick, P. (1956). Minority Report. London: Gollancz.

Dobos, C. (1992). Defining risk from the perspective of nurses in clinical roles. Fournal of Advanced Nursing, 17, 1303-1309.

European Court of Human Rights (1998). Human Rights Act (European Court of Human Rights).

Foucault, M. (1961). Madness and Civilization. London: Penguin.

Garza-Trevino, E. (1994). Neurobiological factors in aggressive behaviour. Psychiatric Services, 46(9), 91-94.

Goldacre, B. (2002). When hospital is a prison. Guardian, 16(July), p. 6.

Gostin, L. (1985). Representing the mentally Ill and handicapped. A guide to mental health review tribunals. London: National Association for Mental Health and The Legal Action Group.

Gotz, M., Johnstone, E., \& Ratcliffe, S. (1999). Criminality and antisocial behaviour in unselected men with sex chromosome abnormalities. Psychological Medicine, 29(4), 953-962.

Hacking, I (1990). The taming of chance. Cambridge: Cambridge University Press.

Hawkins, J., \& Allen, R. (Eds.) (1991). The Oxford Encyclopaedic English Dictionary. Oxford: Clarendon Press.

Hayes, M. (1992). On the epistemology of risk: language, logic and social science. Social Science E Medicine, 35(4), 401-407.

Home Office and Department of Health \& Social Security (1975). Mentally abnormal offenders: Report of the committee. Cmnd 6244 Chairman: Lord Butler of Saffron Walden. London: HMSO.

Johnstone, L. (2000). Users and abusers of psychiatry. London: Routledge.

JUSTICE (1999). Managing dangerous people with severe personality disorder. (Response to Government consultation paper December 1999) London: JUSTICE. Available at: www.justice.org.uk (accessed 20 June 2003).

Kalat, J. (1992). Biological psychology. London: Wadsworth.

Kinsey, A. (1947). Sexual behaviour in the human male. New York: Saunders.

Laing, R. D. (1960). The divided self. London: Tavistock Publications.

LePage, J. (1999). The impact of a token economy on injuries and negative events on an acute psychiatric unit. Psychiatric Services, 50(7), 941-944.

Lupton, D. (1994). Moral threats and dangerous desires. AIDS in the news media. London: Taylor \& Francis.

Lupton, D. (1995). The imperative of health: Public health and the regulated body. London: Sage.

Lupton, D. (1999). Risk (Key Ideas S.). London: Routledge.

Megargee, E. (1976). The prediction of dangerous behaviour. Criminal fustice and Behaviour, 3, 3-22.

Monahan, J. (1984). The prediction of violent: toward a second generation of theory and policy. American fournal of Psychiatry, 141(1), 10-15.

Monahan, J. (1988). Coercion and commitment: understanding involuntary mental hospital admission. International Fournal of Law E Psychiatry, 18(3), 249-263.

Morrison, E. (1994). The evolution of a concept: aggression and violence in psychiatric settings. Archives of Psychiatric Nursing, 8(4), 245-253.

Morrison, E. (1998). The culture of care giving and aggression in psychiatric settings. Archives of Psychiatric Nursing, 12(1), 21-31.

Nietzel, M., Speltz, M., McCauley, E., \& Berstein, D. (1998). Abnormal Psychology. London: Allyn \& Bacon. 
Nisbett, R., \& Ross, L. (1980). Human inference: Strategies and shortcomings in social judgement. London: Prentice-Hall.

Norton, K., \& Dolan, B. (1995). Acting out and the institutional response. Fournal of Forensic Psychiatry, 6(2), 317-332.

Nursing and Midwifery Council (2002). Code of Professional Conduct. London: NMC.

Owen C., Trantello, C., Jones, M., \& Tennant, C. (1998). Violence and aggression in psychiatric units. Psychiatric Services, 49(11), 1452-1457.

Petersen, A., \& Lupton, D. (1996). The new public health: Health and self in the age of risk. London: Sage.

Philo, G., Secker, J., Platt, S., Hendersen, L., \& Burnside, J. (1994). The impact of the mass media on public images of mental illness: media content and audience belief. Health Education fournal, 53, $271-281$.

Quinsey, V. (1995). The prediction and explanation of criminal violence. International fournal of Psychiatry and Law, 13, 207-215.

Ramon, S. (1996). Psychiatry in Britain: Meaning and policy. London: Croom Helm.

Rogers, C. (1961). On becoming a person. London: Houghton.

Sawer, P. (2002). No way to predict Satanist's killing. Daily Mail, 22(March), p. 3.

Steadman, H., \& Cocozza, J. (1980). The duty to protect in private practice. London: Thomas.

Stokman, C. (1984). Dangerousness and violence in hospitalised mentally ill offenders. Psychiatric Quarterly, 56(2), $138-143$.

Swanson, J., Holzer, C., Ganju, V., \& Tsutomu Jono, R. (1990). Violence and psychiatric disorder in the community: evidence from the epidemiological catchment area surveys. Hospital and Community Psychiatry, 41(7), 761-770.

Taylor, P., \& Gunn, J. (1999). Homicides by people with mental illness: myth and reality. British fournal of Psychiatry, 174, 9-14.

Vinestock, M. (1996). Risk assessment: 'A word to the wise'?. Advances in Psychiatric Treatment, 2, 3-10.

Warner, R. (1994). Recovery from schizophrenia: Psychiatry and political economy. London: Routledge.

Wilson, J. (2002). Breach of human rights could start flood of claims by detained patients. Guardian, 24 (April), p. 7.

Wilson, H., \& Kneisl, C. (1988). Psychiatric nursing. London: Addison Wesley. 